\title{
Make-Up and Suspicion in bargaining with cheap talk. An experiment controlling for gender and gender constellation
}

\author{
D. Di Cagno*, A. Galliera ${ }^{\dagger}$, W. Güth ${ }^{\ddagger}$, N. Pace ${ }^{\S}$, L. Panaccione
}

March 30, 2015

\begin{abstract}
This paper explores gender differences in "make- up" and "suspicion" in a bargaining game in which the privately informed seller of a company sends a value message to the uninformed potential buyer who then proposes a price for the company. "Make-up" is measured by how much the true value is overstated, "suspicion" by how much the price offer differs from the value message. We run different computerized treatments varying in information about the gender (constellation) and in embeddedness of gender information. The asymmetry of the game and of information allows for a robust assessment of gender (constellation) effects. We report here the results from just one shot round decision since we expect such effects to be more pronounced for inexperienced participants. We mainly find an effect of gender constellation: when female sellers are aware to confront a female buyer, they overstate more, i.e. there is more "make-up". However, we cannot confirm gender (constellation) effects for suspicion.
\end{abstract}

Keywords: bargaining, cheap-talk, experiment, gender.

JEL: C78; C91; J16

*Luiss Guido Carli University of Rome, Rome, Italy. E-mail: ddicagno@luiss.it

${ }^{\dagger}$ Luiss Guido Carli University of Rome, Rome, Italy. E-mail: agalliera@luiss.it

${ }^{\ddagger}$ Luiss Guido Carli University of Rome, Italy, Frankfurt School of Finance and Management, Max Planck Society at the MPI on Collective Goods, Bonn, Germany. E-mail: gueth@coll.mpg.de

$\S$ University Ca’ Foscari of Venice, Venice, Italy. E-mail: n.pace@unive.it

"DEDI and CEIS, University of Rome "Tor Vergata". E-mail: luca.panaccione@uniroma2.it 


\section{Introduction}

Much of gender research in experimental economics focus on differences in risk, delay, inequity, ... aversion to explain differences in subjects' choices. In this study, we are interested in the rather different hypothesis that, due to gender specific characteristics in bargaining, women are more suspicious than men and feel less obliged to tell the truth. This hypothesis is based on the evidence that persons belonging to groups that historically have been discriminated against (e.g., minorities and women) are less likely to trust and therefore behaving more strategically (Alesina and La Ferrara, 2002). Therefore, women could have evolved as relatively more risk averse (Eckel and Grossman, 2008), but also superior in detecting others' trustworthiness and in strategizing (Buss, 2005). So far the evidence for such hypotheses is inconclusive (Eagly and Wood, 1999).

We aim at verifying that women are more suspicious and strategizing than men by using a modified "Acquiring-a-Company" game (Samuelson and Bazerman, 1985), in which the seller of the company, after learning its value, can strategize when sending a value message to the potential buyer. The buyer then proposes a price after having received the message without, but knowing the value of the firm. ${ }^{1}$ Since the message can be truthful or not, the price offer will reflect not only the desired share of surplus from trade but also the buyer's suspicion: for a more suspicious buyer the difference of the message received and the price proposed should be larger.

Since the experimental setting is one of bargaining whether to trade and, if so, at which price, our study is in line with those on gender differences in bargaining (Ayres and Siegelman 1995; Eckel and Grossman, 2001; Saad and Tripatl, 2001; Solnick, 2001; Riley and McGinn 2002; Gneezy and Rustichini, 2004; Niederle and Vesterlund, 2007; Sutter et al. 2009; García-Gallego 2012). We add new insights to this strand of gender research since we study how "make up", i.e. seller's overstatement of the firm's true value and "suspicion", i.e. buyer's underpricing of the value message, depend on gender and gender constellation. Furthermore, we study how seller's acceptance of price offers depends on gender and gender constellation. ${ }^{2}$

We expected women to "make-up" (strategize) more, to be more "suspicious" (underprice more), and to accept to trade more frequently when bar-

\footnotetext{
${ }^{1}$ The "Acquiring-a-Company" game is often used as a simple environment to analyze the "winner's curse" (Kagel 1995, Thaler 1988). In a companion paper, we provide an analysis of this effect by using the data from repeated rounds (see Di Cagno et al. 2015).

${ }^{2}$ This step of the decision process resembles an ultimatum game. Therefore, our findings can be compared to the results of gender differences in that framework.
} 
gaining with female rather than with male partners.

Our results are based on the first paid round of an experiment which includes subsequent repeated rounds. We concentrate here on this set of data since we expect gender differences to emerge more clearly from choice behavior of inexperienced participants, for whom the offsetting effect of experience and learning are absent.

We find a significant effect of the female-female constellation for making up, i.e. sending value messages which overstate the true value of the firm. On the contrary, the experimental hypothesis that women are more suspicious than men is not confirmed by our analysis. However, the latter finding has to be interpreted with care since suspicion, measured as underpricing the value message, confounds the limited trust of that message with asking for a higher share from the surplus of trade.

\section{The Game and the Experiment Setup}

We consider a modified "Acquiring-a-Company" game in which the seller, after learning the firm's value $v$, can send a value message $\hat{v}=\hat{v}(v)$ to the potential buyer (Güth et al., 2014). The value of the firm is known only to the seller and is randomly generated according to the uniform density, concentrated on the interval $(0,1)$. The seller's evaluation of the firm is $q v$ with $0<q<1$. The parameter $q$ is exogenously given and commonly known. After receiving the value message $\widehat{v}$, the buyer proposes a price $p=p(\hat{v})$ for acquiring the company. If trade occurs, the gains from trade are $v-p$ for buyer and $p-q v$ for seller, hence the surplus amounts to $(1-q) v$, which is always positive. The seller can accept or reject the offer, after which the game ends. The payoff is $\delta(p-q v)$ for the seller and $\delta(v-p)$ for the buyer, where $\delta=\delta(p, \widehat{v}, v)=1$ if the offer is accepted and $\delta=\delta(p, \widehat{v}, v)=0$ if it is rejected. According to the benchmark solution, under the assumption of risk neutrality, the buyer offers

$p^{*}=0$ when $q>\frac{1}{2}$, which the seller rejects, and $p^{*}=q$ when $q \leq \frac{1}{2}$, which the seller accepts.

We run an experiment aimed at analyzing subjects' acceptance decisions, "make-up" - measured by the difference between the value message $\hat{v}$ and the true value $v$ - and "suspicion" - measured by the difference between the value message $\hat{v}$ and the price offer $p$ - by controlling not only for gender but also for gender constellation. To this aim, we ran twelve gender-balanced sessions at the laboratory of Max Planck Institute in Jena. A total of 376 students of different disciplines (11 sessions of 32 participants plus 1 session of 24) were recruited among the undergraduate population of Jena University 
using Orsee (Greiner, 2004). The experiment was fully computerized using z-Tree (Fischbacher, 2007). ${ }^{3}$

At the beginning of the experiment, half of participants were assigned to the role of seller and half to the role of buyer. In each session, male and female participants were evenly split in the two roles.

The basic decisions were taken in the following order. First, the computer selects for each seller the value of the firm $v$ according to a discrete uniform distribution on $(0,100)$ and communicates it only to each seller. Second, the computer selects the value of $q$ from a discrete uniform distribution concentrated on $(0,1)$ and communicates it to both sellers and buyers. Third, the seller decides the value message $\widehat{v}$ to send to the buyer. Fourth, after receiving the value message, the buyer decides the price offer and communicate it to the seller. Finally, the seller decides whether to accept it or not. If she accepts, the firm will be sold at the offered price, while, if she does not, no trade takes place. At the end of the round, the payoffs of buyers and sellers are calculated by the computer and individually communicated.

We framed this decision process in three treatments differing in information only: in treatment $\mathrm{U}$ (Unknown), trading partners, randomly matched in pairs, are unaware of other's gender, which is known in treatment G (awareness of gender constellations). Finally, in treatment E (embedded information about the gender constellation) the field of study of both partners is added to information on gender in order to control for demand effects.

\section{Main Findings}

Proceeding as in backward induction, we begin with analyzing acceptance decisions $\delta$ by seller participants as depending on the profitability of the price offer. $^{4}$

Observation 1 One mainly observes the predicted theoretical rational behavior: $\delta=1$ for $p \geq q v$ and $\delta=0$ for $p<q v$. There exist no gender (constellation) effect in acceptance behavior of seller participants (see Table 1).

These findings suggest that acceptance decision does not depend on the share of surplus that the seller aims to gain and question other-regarding

\footnotetext{
${ }^{3}$ After reading the instructions (available from the authors upon request), participants had to answer a few control questions before the experiment started.

${ }^{4}$ What this neglets is a direct effect of the parameter $q$ and the value $v$, which together determine the surplus from trade, as well as of $\widehat{v}$. We also checked the direct effect of $q$ and $v$ and the results do not change.
} 
Table 1: Seller's acceptance $\delta$ by treatment and gender

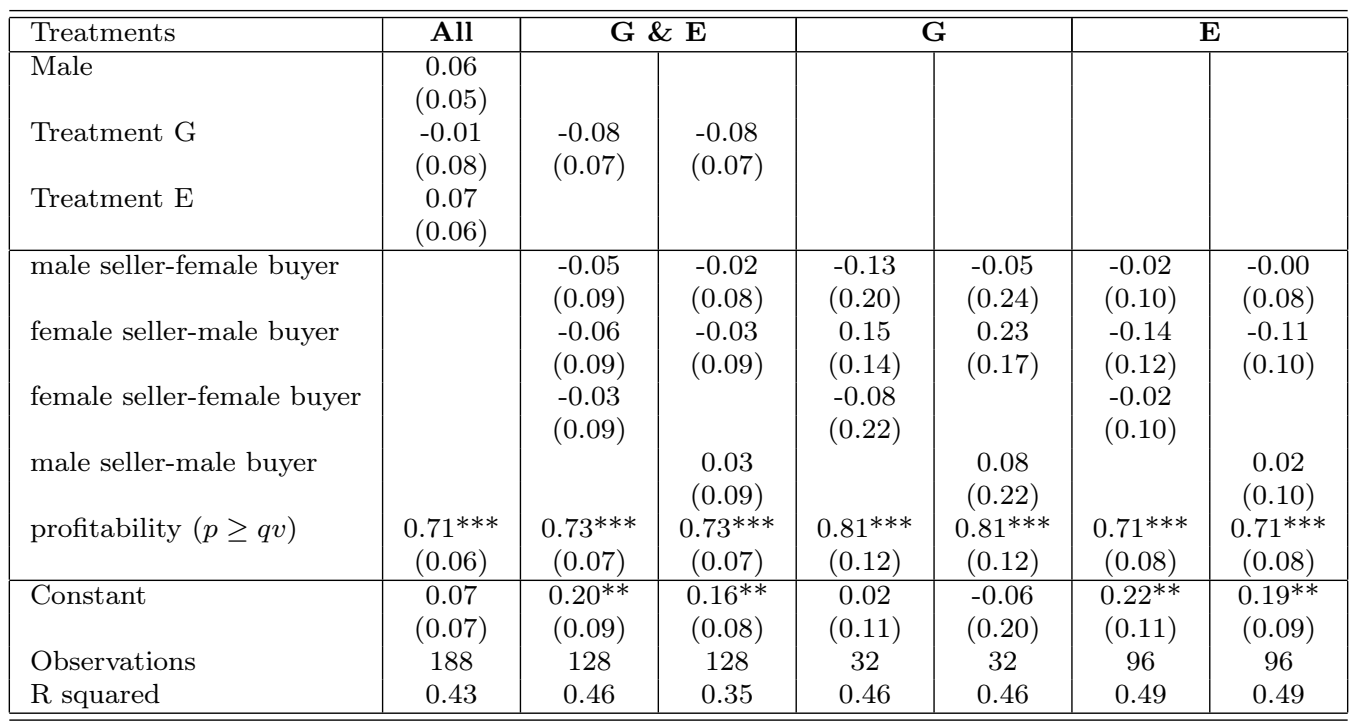

Notes: OLS regressions. Coefficients and Huber-White robust standard errors (in parenthesis) are reported.

Significance: * $0.1, * * 0.05, * * * 0.01$

concerns: at least for situations when own generosity would let the other gain whereas oneself suffers a (minor) loss, there is no evidence of pro-social behavior according to acceptance data (only $1.8 \%$ of sellers accepted to trade when $p<q v$ ). The seller accepts whenever he or she finds it convenient and his or her decision is not affected by a strategic behavior related to the price offer.

As far as "suspicion" is concerned, the price offer by the buyer could be influenced not only by suspiciousness about the value message but also by the desire to obtain a higher share of the surplus from trade. Thus a buyer who thinks the value message is truthful, i.e. expects $\hat{v}(v)=v$, may well propose a price $p<\hat{v}$. Actually, for ultimatum experiments, Eckel and Grossman (2001) find that women as proposer are more generous than men, that, in our set up, corresponds to offering a higher price. Thus more suspiciousness by female buyers could be compensated by more generous price offers. We do not claim to distinguish pure suspicion and underpricing to guarantee a satisfactory own share of the surplus but only maintain that more "suspicion" should increase $\hat{v}-p$.

Observation 2 Male and female buyers do not differ in "suspicion", i.e. we 
Table 2: Buyer's offered price $p$ by treatment and gender

\begin{tabular}{|l|c|c|c|c|c|c|c|}
\hline \hline Treatments & All & \multicolumn{2}{|c|}{ G \& E } & \multicolumn{2}{|c|}{ G } & \multicolumn{2}{c|}{ E } \\
\hline Male & 0.73 & 3.70 & & 6.65 & & 3.89 & \\
& $(7.18)$ & $(8.35)$ & & $(22.38)$ & & $(9.24)$ & \\
Male $\times \hat{v}$ & -0.02 & -0.04 & & -0.06 & & -0.05 & \\
& $(0.14)$ & $(0.16)$ & & $(0.40)$ & & $(0.18)$ & \\
Partner: Male & & & -4.28 & & $-28.97^{*}$ & & 2.49 \\
& & & $(8.59)$ & & $(15.64)$ & & $(9.54)$ \\
Partner Male $\times \hat{v}$ & & & 0.08 & & $0.49^{*}$ & & -0.03 \\
& & & $(0.16)$ & & $(0.26)$ & & $(0.18)$ \\
\hline Treatment G & 2.39 & 2.14 & 2.51 & & & & \\
Treatemtn E & $(3.28)$ & $(3.05)$ & $(2.91)$ & & & & \\
& 0.06 & & & & & & \\
q & $(2.49)$ & & & & & \\
& $0.15^{* * *}$ & $0.18^{* * *}$ & $0.18^{* * *}$ & $0.22^{* *}$ & $0.21^{* *}$ & $0.17^{* * *}$ & $0.17^{* *}$ \\
$\hat{v}$ & $(0.05)$ & $(0.05)$ & $(0.05)$ & $(0.10)$ & $(0.09)$ & $(0.06)$ & $(0.07)$ \\
& $0.49^{* * *}$ & $0.47^{* * *}$ & $0.41^{* * *}$ & $0.57^{* *}$ & 0.30 & $0.45^{* * *}$ & $0.45^{* * *}$ \\
Constant & $(0.09)$ & $(0.10)$ & $(0.10)$ & $(0.27)$ & $(0.21)$ & $(0.11)$ & $(0.12)$ \\
\hline & -0.53 & -1.65 & 2.39 & -8.08 & 11.03 & -0.35 & 0.28 \\
Observations & $(4.91)$ & $(5.65)$ & $(4.55)$ & $(19.50)$ & $(12.51)$ & $(6.00)$ & $(4.93)$ \\
R-squared & 188 & 128 & 128 & 32 & 32 & 96 & 96 \\
\hline \hline
\end{tabular}

Notes: OLS regressions. Coefficients and Huber-White robust standard errors (in parenthesis) are reported.

Significance: $* 0.1, * * 0.05, * * * 0.01$

cannot reject that $\hat{v}-p$ is homogeneously distributed for male and female buyer participants.

Note, however, the significantly lower prices offered to male sellers in Treatment G (see Table 2). ${ }^{5}$ This evidence could be explained by expecting that male sellers overstate more, contrary to our "make-up" hypothesis, or by discrimination of male sellers. Actually, Observation 3 below suggests no difference in overstating which supports the latter explanation.

Observation 2 as such does not question the hypothesis that women have evolved as more skeptical. The fact that we do not observe significant gender (constellation) differences in our measure of suspiciousness may be due to male buyers asking for a higher own share of the surplus from trade. This would suggest that male sellers reveal more ambition also by more make up so that the difference $\hat{v}-v$ is larger for them than for female sellers. This, however, can be rejected, as the following observation makes clear.

Observation 3 Male and female sellers do not differ in "make up", i.e. we cannot reject that $\hat{v}-v$ is homogeneously distributed for male and female seller

\footnotetext{
${ }^{5}$ This result is quite in contrast to the finding of Garcia-Gallego et al. (2012) in a field experiment.
} 
Table 3: Seller's "make-up" $(\hat{v}-v)$ by treatment and gender

\begin{tabular}{|l|c|c|c|c|c|c|c|}
\hline \hline Treatments & All & \multicolumn{2}{|c|}{ G \& E } & \multicolumn{2}{|c|}{ G } & \multicolumn{2}{c|}{ E } \\
\hline Male & 1.49 & 1.53 & & -4.25 & & 3.46 & \\
& $(2.70)$ & $(3.43)$ & & $(6.85)$ & & $(3.97)$ & \\
Partner: Male & & & -2.50 & & $-17.63^{* * *}$ & & 2.54 \\
& & & $(3.43)$ & & $(6.09)$ & & $(3.97)$ \\
\hline Treatment G & -1.54 & 0.81 & 0.81 & & & & \\
& $(3.99)$ & $(3.93)$ & $(3.84)$ & & & & \\
Treatment E & -2.35 & & & & & & \\
& $(2.90)$ & & & & & & \\
\hline Constant & $5.86^{* *}$ & 3.48 & $5.50^{* *}$ & 7.19 & $13.88^{* * *}$ & 2.52 & 2.98 \\
& $(2.38)$ & $(2.53)$ & $(2.74)$ & $(5.32)$ & $(4.00)$ & $(2.68)$ & $(2.94)$ \\
Observations & 188 & 128 & 128 & 32 & 32 & 96 & 96 \\
R-squared & 0.005 & 0.002 & 0.005 & 0.013 & 0.218 & 0.008 & 0.004 \\
\hline \hline
\end{tabular}

Notes: OLS regressions. Coefficients and Huber-White robust standard errors (in parenthesis) are reported.

Significance: * $0.1, * * 0.05, * * * 0.01$

participants (see Table 3).

Even though there is no gender effect on making up, we find a gender constellation effect since, as stated by Observation 4, female sellers trading with female buyers "make-up" significantly more.

Observation 4 In treatment $G$, there is more "make-up" in the female-female constellation, i.e. there is evidence that women are more strategizing by overstating more, quite surprisingly, confronting a female buyer (see Table 4).

To further investigate the making up attitude, we report in Table 5 the probabilities of stating a value message equal, greater or lower than the true value of the firm for the pooled data from treatments $\mathrm{G}$ and $\mathrm{E}$, which provide common knowledge of gender constellation.

There is quite some heterogeneity in value messages sent by sellers: $52.13 \%$ of them overstate $(\hat{v}(v)>v), 26.60 \%$ understate $(\hat{v}(v)<v)$, and $21.28 \%$ are truthful $(\hat{v}(v)=v)$. Furthermore, consistently with Observation 4, we find a significant gender constellation effect on the probability of overstating $(P=$ 0.046). Therefore, we conclude that average overstating and its probability are larger for the female-female constellation.

\section{Conclusions}

By a modification of the "Acquiring-a-Company" game, we studied in the lab how "make-up", "suspicion" and acceptance in bargaining depend on gender 
Table 4: Seller's "make-up" $(\hat{v}-v)$ by treatment and gender constellation

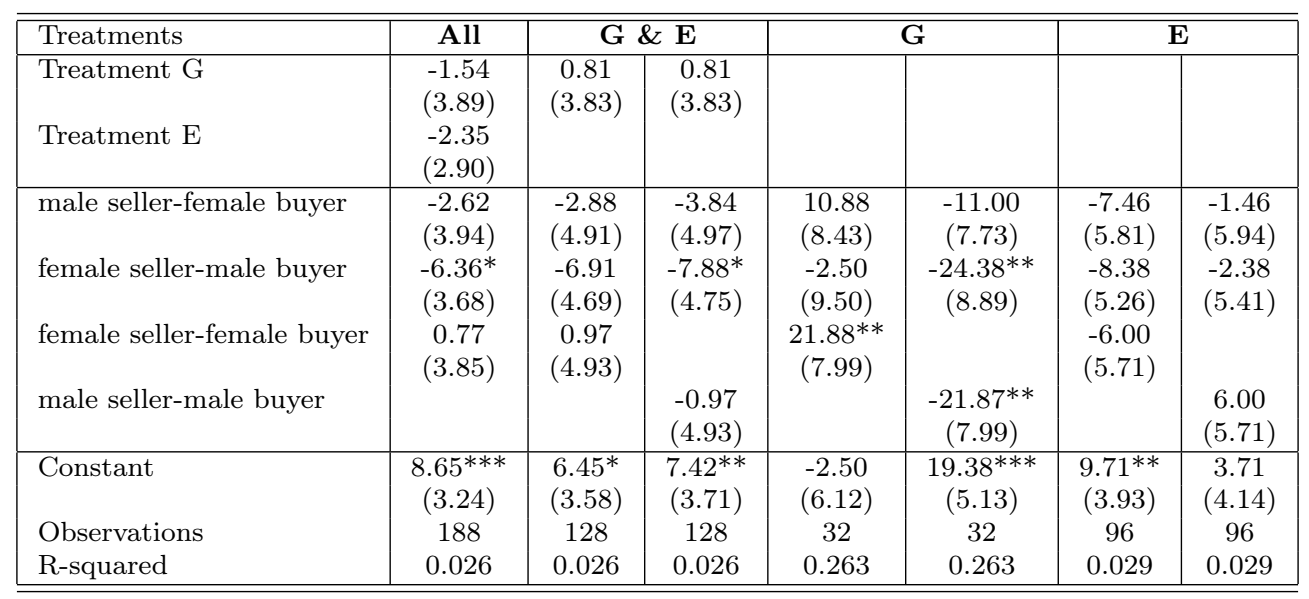

Notes: OLS regressions. Coefficients and Huber-White robust standard errors (in parenthesis) are reported.

Significance: * $0.1, * * 0.05, * * * 0.01$

Table 5: Truthtelling, overstating and understating the value message by gender and gender constellation

\begin{tabular}{|l|c|c|c|c|}
\hline \hline & & female seller & male seller & P-value \\
\hline Truthtelling & & 24.47 & 18.09 & 0.288 \\
& female buyer & 21.88 & 15.63 & \\
& male buyer & 31.25 & 21.88 & \\
& $P$-value & 0.404 & 0.529 & \\
\hline \hline Overstating & & 50.00 & 54.26 & 0.562 \\
& female buyer & 59.38 & 46.88 & \\
& male buyer & 34.38 & 59.38 & \\
& $P$-value & 0.046 & 0.324 & \\
\hline \hline Understating & & 25.53 & 27.66 & 0.743 \\
& female buyer & 18.75 & 37.50 & \\
& male buyer & 34.38 & 18.75 & \\
& $P$-value & 0.162 & 0.098 & \\
\hline \hline
\end{tabular}

Notes: This table considers data from Treatment G and Treatment E. 
and gender constellation.

We find that female sellers make up significantly more and more frequently when matched with the same gender.

There is a surprising degree of truth-telling and an even higher degree of understating which, however, do not differ across gender and gender constellations. Moreover, we find no gender nor gender constellation effect on acceptance and no evidence of pro-social behavior, not even in those situations when generosity would let the other gain a lot at minor own loss. However, we can confirm that women are more strategizing by overstating more and more likely when confronting a female buyer.

Finally, at first sight it may seem that not being able to confirm that women are more suspicious is not consistent with the literature which finds significant, though conflicting, gender effects. Eckel and Grossman (2001) show that women are more generous as proposers in ultimatum experiments while Garcia-Gallego et al. (2012) argue that they are less generous, and also question the relevance of risk attitude. ${ }^{6}$

However, in our setting with asymmetric information and stochastic uncertainty "take-it-or-leave-it" price offers may not be gender (constellation) biased since trusting the value of the message is confounded with asking a higher share of surplus. Decoupling these two effects has been analyzed by assuming that more or less ambition in demanding a larger surplus share from trade should go along with more or less ambition in overstating. Since the latter is not significantly affected by gender (constellation) we could not confirm that women are more suspicious although we partly found them to be more often and to a larger extent strategizing.

\section{Acknowledgments}

We would like to thank the Max Planck Institute of Jena for funding and supporting this research.

The authors declare that there are no conflicts of interest.

\section{References}

Alesina, A., and La Ferrara E., 2002. Who trusts others? Journal of Public Economics, 85(2), 207-234.

\footnotetext{
${ }^{6}$ According to our data, risk attitude does not affect the results.
} 
Ayres, I., and Siegelman P., 1995. Race and Gender Discrimination in Bargaining for a New Car. American Economic Review, 85(3), 304-321.

Buss, D. M. (ed.), 2005. The Handbook of Evolutionary Psycology, Wiley.

Di Cagno, D., Galliera, A., Güth, W., Pace, N., Panaccione, L., 2015. Experience and Gender Effects in an Acquiring-a-Company Experiment allowing for Value Messages, mimeo.

Eagly, A. H., and Wood, W., 1999. The origins of sex differences in human behavior: Evolved dispositions versus social roles. American Psychologist, 54, 408-423.

Eckel, C.C., and Grossman, P.J., 2001. Chivalry and Solidarity in Ultimatum Games, Economic Inquiry, 39(2), 171-188.

Eckel, C.C., and Grossman, P.J., 2008. Men, Women and Risk Aversion: Experimental Evidence in Handbook of Experimental Economics Results (Plott C. and Smith V. eds.) vol.1, Ch.113, pp. 1061-1073.

Fischbacher, U., 2007. z-Tree: Zurich toolbox for ready-made economic experiments. Experimental Economics, 10(2), 171-178.

García-Gallego, A., Georgantzís, N., Jaramillo-Gutiérrez, A., 2012. Gender differences in ultimatum games: Despite rather than due to risk attitudes, Journal of Economic Behavior \& Organization, 83(1), 42-49.

Gneezy, U., and Rustichini, A., 2004. Gender and Competition at a Young Age. American Economic Review, 94(2), 377-381.

Greiner, B., 2004. The online recruitment system orsee 2.0-a guide for the organization of experiments in economics, University of Cologne, Working paper series in economics, 10(23), 63-104.

Güth, W., Pull K., Stadler, M., Zaby A., 2014. Compulsory Disclosure of Private Information: Theoretical and Experimental Results for the "Acquiring-a-Company" Game, Jena Economic Research Paper 2014-003.

Kagel, J.H., 1995. Cross-game learning: Experimental evidence from first-price and English common value auctions. Economics Letters, 49(2), 163-170.

Niederle, M., and Vesterlund, L., 2007. Do Women Shy Away from Competition? Do Men Compete Too Much?. The Quarterly Journal of Economics, 122(3), 1067-1101. 
Riley, B.H., and McGinn, K.L., 2002. When Does Gender Matter in Negotiation?. Working Paper Series rwp02-036, Harvard University, John F. Kennedy School of Government.

Saad, G., and Tripat, G., 2001. Sex Differences in the Ultimatum Game: An Evolutionary Psychology Perspective. Journal of Bioeconomics, 3(2), 171193.

Samuelson, W.F., and Bazerman, M. H., 1985. Negotiation under the winner's curse. Research in Experimental Economics, Vol. III, Smith, V. (ed.).

Solnick, S.J., 2001. Gender Differences in the Ultimatum Game. Economic Inquiry, 39(2), 189-200.

Sutter, M., Bosman, R., Kocher M., Winden, F., 2009. Gender pairing and bargaining-Beware the same sex!. Experimental Economics, 12(3), 318331.

Thaler, R., 1988. Anomalies: The Winner's Curse. The Journal of Economic Perspectives, 2(1), 191-202. 